\title{
Associations Between Online Pornography and Sexual Behavior Among Adolescents: Myth or Reality?
}

\author{
Marie-Thérèse Luder • Isabelle Pittet • \\ André Berchtold • Christina Akré • \\ Pierre-André Michaud · Joan-Carles Surís
}

Received: 30 July 2009 / Revised: 9 October 2010 / Accepted: 15 October 2010 / Published online: 3 February 2011

(C) Springer Science+Business Media, LLC 2011

\begin{abstract}
This study aimed to compare the sexual behavior of adolescents who were or were not exposed to online pornography, to assess to what extent the willingness of exposure changed these possible associations, and to determine the profiles of youths who were exposed to online pornography. Data were drawn from the 2002 Swiss Multicenter Adolescent Survey on Health, a self-administered cross-sectional, paper and pencil questionnaire. From the 7529 adolescents aged 16-20 years, 6054 (3283 males) used the Internet during the previous month and were eligible for our study. Males were divided into three groups (wanted exposure, 29.2\%; unwanted exposure, $46.7 \%$; no exposure, $24.1 \%$ ) whereas females were divided into two groups (exposure, 35.9\%; no exposure, 64.1\%). The principal outcome measures were demographic characteristics, Internet use parameters and risky sexual behaviors. Risky sexual behaviors were not associated with online pornography exposure in any of the groups, except that males who were exposed (deliberately or not) had higher odds of not having used a condom at last intercourse. Bi/homosexual orientation and Internet use parameters were not associated either. Additionally, males in the wanted exposure group were more likely to be sensation-seekers. On the other hand, exposed girls were more likely to be students, higher sensation-seekers, early maturers, and to have a highly educated father. We conclude that pornography exposure is not associated with risky sexual behaviors and that the willingness of exposure does not seem to have an impact on risky sexual behaviors among adolescents.
\end{abstract}

M.-T. Luder · I. Pittet · A. Berchtold · C. Akré ·

P.-A. Michaud · J.-C. Surís $(\square)$

Research Group on Adolescent Health, Institute of Social and Preventive Medicine, Centre Hospitalier Universitaire Vaudois and University of Lausanne, Bugnon, 17, 1005 Lausanne, Switzerland

e-mail: joan-carles.suris@chuv.ch
Keywords Pornography - Adolescent sexual behavior . Internet $\cdot$ Gender differences $\cdot$ Health information

\section{Introduction}

Exposure to pornography might affect adolescents in their psychosexual development which, in turn, might result in more permissive sexual norms, less progressive gender attitudes, and even changes in their sexual behavior (Brown \& L'Engle, 2009). The higher rates of risky sexual behaviors among young people who are exposed to pornography (Braun-Courville \& Rojas, 2009; Wingood et al., 2001) (or sexually explicit media [SEM], which will be used as a synonym in this article) imply a higher risk to contract sexually transmitted infections. Of course, these negative medical outcomes are only one aspect of the more global impact pornography might have on adolescent sexual development. Diminished trust in intimate partners, cynical attitudes about love, and dissociation of love and sexuality are only some examples which might affect a healthy sexual socialization process (Zillmann, 2000).

Positive outcomes, especially pornography as a mean of sexual information, have nevertheless also been demonstrated. A study among young adults (18-30 years old) examining the relation between pornography consumption and its self-perceived impact showed a positive effect in diverse areas, such as sexual knowledge and attitudes and general quality of life (Hald $\&$ Malamuth, 2008). Another study showed that only $12 \%$ of male and $18 \%$ of female adolescents exposed to Internet pornography reported an important impact on their emotions or attitudes (Sabina, Wolak, \& Finkelhor, 2008).

It is noteworthy, however, that the cross-lagged links between SEM exposure and risky sexual behaviors have been rarely examined among adolescents (Braun-Courville \& Rojas, 2009; Haggstrom-Nordin, Hanson, \& Tyden, 2005; Wingood 
et al., 2001). It has repeatedly been demonstrated that a pornography-seeking attitude is more prevalent among males (Haggstrom-Nordin et al., 2005; Peter \& Valkenburg, 2006; Wolak, Mitchell, \& Finkelhor, 2007) and is associated with having had sexual intercourse (SI) (Brown \& L'Engle, 2009), multiple lifetime sexual partners (Braun-Courville \& Rojas, 2009; Wingood et al., 2001), and anal (Braun-Courville \& Rojas, 2009) or oral sex (Brown \& L'Engle, 2009). Regarding condom use (non-use being typical in pornographic scenes), Wingood et al. (2001) found that exposure to X-rated movies was linked with negative attitudes towards its use.

Given that the Internet is frequently reported as the most common source of pornography exposure (Haggstrom-Nordin et al., 2005; Stulhofer, Busko, \& Landripet, 2010), adolescents' access to sexually explicit websites raises some concern. Indeed, this media offers the opportunity to have an anonymous and confidential access to sexual health information but, on the other hand, it also provides an access to websites which are normally reserved for adults in one click (Kanuga \& Rosenfeld, 2004).

According to a Kaiser Family Foundation Survey (Rideout, 2009), 70\% of 15-17 year-olds had accidentally come across pornographic websites. Among these youths, high rates of healthinformation-seeking adolescents had accidentally been exposed to those websites "very" or "somewhat" often. In a U.S. nationally representative sample, Wolak et al. (2007) found that $42 \%$ of 10-17 year-old Internet users had been exposed to pornography in the previous year, among which $66 \%$ reported only unwanted exposure. Another result from this study was that wanted exposure was associated to male gender and rule breaking, whereas unwanted exposure was associated to online harassment, offline victimization, and depression.

Overall, deliberate X-rated website exposure has shown to be more prevalent among males (Peter \& Valkenburg, 2006) and unwanted exposure seems to be more frequently reported by females (Sabina et al., 2008). Nevertheless, 30\% of 16-17 year-old male Internet users also reported exclusively accidental online pornography exposure (Wolak et al., 2007).

There are factors described in the literature known to influence both Internet use and pornography consumption. Socioeconomic status (SES) is considered as an important factor because belonging to a higher socioeconomic level might imply being more likely/inclined to have an Internet connection (Duimel \& DeHaan, 2007) while having a lower SES and having less educated parents have been associated with deliberate pornography consumption (Brown \& L'Engle, 2009). Both sensation-seeking (Brown \& L'Engle, 2009; Peter \& Valkenburg, 2006), and depression (Peter \& Valkenburg, 2006) have often been associated with SEM exposure. Moreover, the literature also has shown clinical features of depression to be associated with online pornography-seeking (Ybarra \& Mitchell, 2005) and to unwanted exposure (Wolak et al., 2007). McFarlane, Bull, and Rietmeijer (2002) reported that young adults having ever had a sexual partner through the Internet were more likely to have had same-sex partners and hypothesized that the Internet might be an interesting exploration tool for young adults who might still be unsure of their sexual orientation. Finally, the pubertal maturation status has also shown to be associated with more sexual interest (Brown, Halpern, \& L'Engle, 2005).

Given that data about the association between Internet pornography exposure and sexual behavior are scarce (BraunCourville \& Rojas, 2009; Lo \& Wei, 2005), the first aim of this study was to extend current knowledge by analyzing the association between online pornography exposure and risky sexual behavior in a large nationally representative sample. The assumption underlying this objective was that, as demonstrated for pornography consumption in general (Haggstrom-Nordin et al., 2005), deliberate Internet pornography exposure might be correlated with risky sexual behavior. The second goal of the study was to assess whether unwanted exposure was also associated with risky sexual behavior and the third objective was to characterize online pornography consumers (whether deliberate or not) in terms of sociodemographic factors, Internet use parameters, sexual orientation, perceived pubertal timing, depressive mood, and sensation-seeking.

\section{Method}

\section{Participants}

Data were drawn from the 2002 Swiss Multicenter Adolescent Survey on Health (SMASH02) data base. This cross-sectional nationally representative paper and pencil survey included 7548 adolescents (48.5\% females) aged 16-20 years old, attending post-mandatory education. The sample included adolescents attending high school and those who were employed as apprentices in diverse companies for their training. About $10 \%$ of Swissresident adolescents from this age group were not enrolled in any of these academic tracks and therefore not included in the survey. The questionnaire was anonymous, self-administered, and included items about sociodemographic characteristics, health behaviors, and health care use. The protocol was approved by the Ethics Committee of the University of Lausanne's School of Medicine. The sampling methods and a more detailed description of the questionnaire have been reported elsewhere (Jeannin et al., 2005).

In this study, we analyzed the subpopulation of 6054 adolescents (corresponding to $81.5 \%$ of the total weighted sample $(n=7429)$ ) who connected to the Internet over the last 30 days. They were distributed into three groups: (1) those who deliberately watched pornographic websites (Have you consulted pornographic websites in the last 30 days?) [wanted exposure (WE), $\mathrm{n}=998$ (96.2\% males)], (2) those who were exposed in an unwanted manner (Have you been confronted to pornography on the Internet without searching for it?) [unwanted exposure (UE), $n=2489$ (61.6\% males)] and (3) those who 
were not exposed [no exposure (NE), $\mathrm{n}=2567$ (30.8\% males)]. The participants who reported WE and UE were assigned to the WE group. As the number of observations in the WE female group was too small to permit adequate statistical analyses ( $n=38$, which corresponds to $1.4 \%$ of the females), we merged WE/UE for females.

\section{Measures}

\section{Demographic Characteristics}

To assess participants' sociodemographic characteristics, we considered age, academic track (student/apprentice), and SES. The latter was estimated by two proxy measures, namely the father's and the mother's education levels. These were dichotomized into "low" (mandatory school or less) and "other" (beyond mandatory schooling).

\section{Risky Sexual Behavior}

Four variables were assessed: SI before the age of 15 (yes/no), no condom use at last SI (yes/no), $\geq 4$ lifetime sexual partners (yes/no), and pregnancy/having made a partner pregnant (yes/ no). Participants who did not have a lifetime experience of SI were each time associated with the "no" answerers.

\section{Personality and Behavioral Variables}

Sensation-seeking was measured on a 5-item scale developed on the basis of the work of Gniech, Oettling, and Brohl (1993) (Cronbach's alpha in the present study $=.80$ ). The scale ranged from 0 to 3 , with higher scores indicating higher sensation seeking.

We used the Depressive Tendencies scale, which has proved to be a reliable and valid instrument (Alsaker, 1992; Holsen, Kraft, \& Vitterso, 2000) to assess participants' depressive mood. It included 8 items about feelings of sadness, hopelessness, and unhappiness (Cronbach $\alpha=.89$ in the present study). The scale ranged from 0 (low) to 3 (high).

When considering adolescent sexual behavior, some attitudinal and developmental parameters seem important to be taken into account: the fact of having currently a girlfriend/ boyfriend and lifetime experience of complete SI, which were assessed in a dichotomous way. We assessed adolescent's sexual interests using five statements which described all the possible affective and sexual attractions between males and females. An example of such a statement is: "I am only attracted to people of the same sex as mine, and I imagine that I will only be sexual with persons of the same sex as mine." Based on these statements, two groups were defined: "heterosexuals" and "bi- or homosexuals." Finally, perceived pubertal timing was assessed with the following question: "If you consider the age at which you started your puberty compared to others, would you say you were..." and the possible answers were: "very ahead," "rather ahead," "like them," "rather behind," and "very behind." Those who considered themselves ahead ("very" or "rather") formed the "ahead" group and were compared to the "others." A high correlation (of 94\%) between this approach and the physician's pubertal status assessment has previously been described (BergKelly \& Erdes, 1997).

\section{Internet Use Parameters}

Using a 30 day timeframe, we defined four frequency groups: $<1$ day/week, 1 day/week, $>1$ day/week but not daily, and daily use. As UE seems to be linked with health information seeking online (Rideout, 2009), we also assessed whether participants actually sought out health, sexual or medical information on the Internet.

\section{Statistical Analyses}

As Internet pornography exposure has been shown to be different among males and females (Peter \& Valkenburg, 2006), we conducted all analyses separately by gender. The first step was a bivariate analyses comparing NE-UE-WE among males and NE-UE/WE among females. We used chi-square tests for categorical data and $t$-test or ANOVA for continuous data. Results were given as prevalence or means. After that, we performed a multinomial logistic regression, using NE as the reference group among males and a binary logistic regression comparing NE and UE/WE among females. Standard procedures for automatic variable selection in regressions being known to produce unstable and non-reproducible results (Austin \& Tu, 2004a), we selected explanatory variables using a bootstrap procedure. Ten thousand bootstrap samples were generated and a backward selection was applied on each of them. Variables retained in at least $60 \%$ of the replications were included in the final regression models (Austin \& Tu, 2004b). Results are given as adjusted odds ratio with $95 \%$ CI. We used StataIC10 for bivariate and multivariate analysis, as it allows computing coefficient estimates and variances taking into account the sampling weights. MATLAB 7.1 was used for the bootstrap variable selection procedure.

\section{Results}

Overall, 29.2\% $(\mathrm{n}=959)$ of males and $1.4 \%(\mathrm{n}=38)$ of females deliberately exposed themselves to online pornography during the last 30 days, $46.7 \%(n=1533)$ of males and $34.5 \% \mathrm{n}=$ 956) of females (reported having been exposed to SEM in an unwanted manner whereas $24.1 \%(n=791)$ of males and $64.1 \%(n=1776)$ of females reported no exposure at all. 
Males: Bivariate Analysis

The bivariate analysis indicated that three of the four risky sexual behavior items were significantly $(p<.05)$ associated with Internet pornography exposure. Participants in the WE group were more likely than those from the other two groups to have had their first SI before age 15, to have not used a condom at last SI, and to have had four or more sexual partners. In addition to sexual risk behavior, several characteristics (lifetime experience of SI, sexual orientation, sensation seeking, depressive mood, being a student, and father's education status) and Internet use parameters were also significantly associated with pornography exposure (Table 1).

Males: Multivariate Regression

When taking into account all parameters for which stability among multiple samples was demonstrated by the bootstrap procedure, only the absence of condom use at last SI remained significantly associated with WE. With regards to the sociodemographic characteristics and the Internet use parameters, adolescents who deliberately watched pornography were also more likely to use the Internet frequently, to seek out healthrelated advice on the Internet, and to score higher on the sensation seeking scale. Bi- or homosexual orientation was also more frequent among pornography consumers. Sociodemographic characteristics were not associated with WE.

Similar to WE participants, those adolescents in the UE group were also less likely than NE youths to have used a condom at last SI, more likely to use the Internet frequently, and to have a bi- or homosexual orientation. This group did not differ from NE in terms of sociodemographic parameters. The only differences between the WE and UE groups concerned the fact that youths from the UE group apparently did not seek sexual/ medical advice on the Internet more often and were not greater sensation-seekers than adolescents in the NE group (Table 2).

Table 1 Bivariate comparison between the three male groups $(n=3283)^{\mathrm{a}}$

\begin{tabular}{|c|c|c|c|c|}
\hline Variable & $\begin{array}{l}\text { NE } 24.1 \% \\
(n=791)\end{array}$ & $\begin{array}{l}\text { UE } 46.7 \% \\
(\mathrm{n}=1533)\end{array}$ & $\begin{array}{l}\text { WE } 29.2 \% \\
(\mathrm{n}=959)\end{array}$ & $p$ \\
\hline \multicolumn{5}{|l|}{ Demographic characteristics } \\
\hline Mean age (years) ${ }^{\mathrm{b}}$ & $17.94 \pm .08$ & $17.87 \pm .08$ & $17.95 \pm .09$ & ns \\
\hline Father's education status (low) & $13.46 \%$ & $9.52 \%$ & $16.29 \%$ & $<.01$ \\
\hline Mother's education status (low) & $22.08 \%$ & $18.99 \%$ & $21.84 \%$ & ns \\
\hline Academic track (student) & $19.92 \%$ & $27.81 \%$ & $24.43 \%$ & $<.01$ \\
\hline \multicolumn{5}{|l|}{ Personality and Behavioral variables } \\
\hline Depressive mood ${ }^{\mathrm{b}, \mathrm{c}, \mathrm{d}}$ & $.49 \pm .03$ & $.51 \pm .02$ & $.66 \pm .03$ & $<.0001$ \\
\hline Sensation-seeking ${ }^{\mathrm{b}, \mathrm{c}, \mathrm{d}}$ & $1.56 \pm .03$ & $1.65 \pm .03$ & $1.80 \pm .05$ & $<.0001$ \\
\hline Girlfriend (no) & $60.79 \%$ & $64.12 \%$ & $60.13 \%$ & ns \\
\hline Sexual intercourse (SI) & $59.32 \%$ & $56.9 \%$ & $67.17 \%$ & $<.001$ \\
\hline Bisexual or homosexual orientation & $.30 \%$ & $1.72 \%$ & $2.98 \%$ & $<.01$ \\
\hline Perceived pubertal timing (early) & $21.38 \%$ & $23.12 \%$ & $25.59 \%$ & ns \\
\hline \multicolumn{5}{|l|}{ Risky sexual behaviors } \\
\hline First SI before age 15 & $7.65 \%$ & $6.29 \%$ & $10.41 \%$ & $<.05$ \\
\hline Did not use a condom at last SI & $17.07 \%$ & $21.94 \%$ & $26.29 \%$ & $<.01$ \\
\hline$\geq 4$ sexual partners & $17.70 \%$ & $15.99 \%$ & $24.44 \%$ & $<.05$ \\
\hline Partner's pregnancy (yes) & $1.64 \%$ & $2.08 \%$ & $3.16 \%$ & ns \\
\hline \multicolumn{5}{|l|}{ Internet use parameters } \\
\hline Internet connection frequency & & & & $<.0001$ \\
\hline Less than one day/week & $33.76 \%$ & $17.16 \%$ & $10.8 \%$ & \\
\hline One day/week & $20.48 \%$ & $18.32 \%$ & $15.87 \%$ & \\
\hline More then one day/week but not daily & $31.70 \%$ & $40.28 \%$ & $37.2 \%$ & \\
\hline Daily & $14.06 \%$ & $24.24 \%$ & $36.13 \%$ & \\
\hline Seeking for sexual or medical advice on the Internet & $8.15 \%$ & $12.42 \%$ & $37.24 \%$ & $<.0001$ \\
\hline
\end{tabular}

\footnotetext{
a The sample size for each analysis varies between 3118 and 3283 due to a small number of missing data

b Mean \pm SE

c WE significantly different from UE and WE significantly different from NE

d Scale from 0 (low) to 3 (high), expressed as means
} 
Table 2 Multinomial regression for males, NE being the reference group ${ }^{\mathrm{a}}$

\begin{tabular}{|c|c|c|c|c|}
\hline Variable & $\begin{array}{l}\text { UE adjusted odds ratio } \\
\text { (95\% confidence interval) }\end{array}$ & Value & $\begin{array}{l}\text { WE adjusted odds ratio } \\
\text { ( } 95 \% \text { confidence interval) }\end{array}$ & $p$ \\
\hline \multicolumn{5}{|l|}{ Demographic characteristics } \\
\hline Age & $.97(.85-1.11)$ & .7 & $.92(.78-1.08)$ & ns \\
\hline Father's education status & $.8(.53-1.2)$ & .3 & $1.45(.95-2.21)$ & ns \\
\hline \multicolumn{5}{|l|}{ Personality and behavioral variables } \\
\hline Sensation-seeking & $1.04(.86-1.26)$ & .7 & $1.29(1.04-1.6)$ & $<.05$ \\
\hline Sexual intercourse (SI) & $.84(.62-1.13)$ & .3 & $1.16(.84-1.6)$ & ns \\
\hline Bisexual or homosexual orientation & $4.51(1.22-16.66)$ & .02 & $6.08(1.67-22.04)$ & $<.01$ \\
\hline \multicolumn{5}{|l|}{ Risky sexual behaviors } \\
\hline Did not use a condom at last SI & $1.55(1.09-2.2)$ & .02 & $1.59(1.08-2.35)$ & $<.05$ \\
\hline \multicolumn{5}{|l|}{ Internet use parameters } \\
\hline \multicolumn{5}{|l|}{ Internet connection frequency } \\
\hline One day/week & $1.75(1.32-2.32)$ & $<.0001$ & $2.31(1.53-3.48)$ & $<.0001$ \\
\hline More than one day/week but not daily & $2.31(1.68-3.19)$ & $<.0001$ & $3.66(2.55-5.25)$ & $<.0001$ \\
\hline Daily & $3.13(2.24-4.39)$ & $<.0001$ & $7.05(4.51-11)$ & $<.0001$ \\
\hline Seeking for sexual or medical advice on the Internet & $1.29(.89-1.85)$ & .2 & $4.43(2.98-6.59)$ & $<.0001$ \\
\hline
\end{tabular}

a The logistic regression uses explanatory factors selected from the bootstrap procedure

Females: Bivariate Analysis

When comparing the WE/UE group (which included only $1.4 \%$ of adolescents who were deliberately seeking online pornography) to the NE group in a bivariate analysis, the only sexual risk parameter associated with pornography exposure was having had the first SI before age 15. As for males, Internet use parameters, lifetime experience of SI, father's education level, being a student, and sensation seeking were all significant characteristics. However, no associations were found for girls regarding their sexual orientation and their scores on the Depressive Tendencies scale. Unlike their male counterparts, females exposed to online pornography were less likely to have a mother with a low education level and were more likely to report an early pubertal status compared to their NE peers (Table 3).

\section{Females: Binary Regression}

As no risky sexual behavior parameters were sufficiently stable among the 10,000 bootstrap replications, the binary logistic regression only permitted an analysis of the association between UE/ WE and Internet use parameters, age, father's education status, academic track, sensation-seeking, and perceived pubertal timing. The girls who were exposed to pornography were more likely to be students and less likely to have a father with a lower education level, to connect to the Internet more frequently, and to seek out medical/sexual advice on the Internet. They were also more likely to report a more advanced pubertal status and to score higher on the sensation-seeking scale (Table 4).

\section{Discussion}

Consistent with other studies (Goodson, McCormick, \& Evans, 2001; Peter \& Valkenburg, 2006), online pornography exposure seemed to be a gendered issue in our research. Indeed, $74 \%$ of boys were exposed to SEM on the Internet in the previous month, whereas only $36 \%$ of females reported some exposure. Regarding the prevalence of unwanted exposure, it is noteworthy that accidental exposure rates were high among males $(46.7 \%)$ and females $(34.5 \%)$. These high rates were consistent with previous research analyzing 10-17 year-olds who accidentally came across pornographic websites, although there were no significant gender differences (Wolak et al., 2007). It could be hypothesized that females are less interested in pornography or that they might under-report their exposure to a higher degree than males.

With respect to sociodemographic characteristics, while we found no relevant associations among males, online pornography exposure among females was associated with a higher education level of the father and the fact of being a student. These associations support the findings from a recent report which found that adolescents in the lower echelons of secondary education (which would correspond to apprentices in our study) were less likely to use the Internet for information purposes (Duimel \& DeHaan, 2007) and from the Kaiser Family Survey (Rideout, 2009) indicating that unwanted exposure was more frequent among online health-advice-seekers, which could be a way of accidentally being confronted to pornography.

As expected, Internet-use parameters were highly correlated with online pornography exposure for both genders. As 
Table 3 Bivariate comparison between the two female groups ${ }^{\mathrm{a}}$

\begin{tabular}{|c|c|c|c|}
\hline Variable & $\begin{array}{l}\text { NE } 64.1 \% \\
(\mathrm{n}=1776)\end{array}$ & $\begin{array}{l}\text { UE/WE } 35.9 \% \\
(\mathrm{n}=995)\end{array}$ & $p$ \\
\hline \multicolumn{4}{|l|}{ Demographic characteristics } \\
\hline Mean age (years) ${ }^{\mathrm{b}}$ & $17.84 \pm .05$ & $17.75 \pm .06$ & $\mathrm{~ns}$ \\
\hline Father's education status (low) & $14.88 \%$ & $9.65 \%$ & $<.01$ \\
\hline Mother's education status (low) & $21.76 \%$ & $17.36 \%$ & $<.05$ \\
\hline Academic track (student) & $37.25 \%$ & $49.25 \%$ & $<.0001$ \\
\hline \multicolumn{4}{|l|}{ Personality and behavioral variables } \\
\hline Depressive mood ${ }^{\mathrm{b}, \mathrm{c}}$ & $.79 \pm .02$ & $.85 \pm .04$ & $\mathrm{~ns}$ \\
\hline Sensation-seeking ${ }^{\mathrm{b}, \mathrm{c}}$ & $1.17 \pm .03$ & $1.30 \pm .04$ & $<.001$ \\
\hline Boyfriend (no) & $53.36 \%$ & $47.42 \%$ & ns \\
\hline Sexual intercourse (SI) & $54.96 \%$ & $61.66 \%$ & $<.05$ \\
\hline Bisexual or homosexual orientation & $2.21 \%$ & $3.15 \%$ & ns \\
\hline Perceived pubertal timing (early) & $28.28 \%$ & $34.60 \%$ & $<.01$ \\
\hline \multicolumn{4}{|l|}{ Risky sexual behaviors } \\
\hline First SI before age 15 & $4.64 \%$ & $6.98 \%$ & $<.05$ \\
\hline Did not use a condom at last SI & $29.50 \%$ & $35.16 \%$ & $\mathrm{~ns}$ \\
\hline$\geq 4$ sexual partners & $9.77 \%$ & $11.81 \%$ & ns \\
\hline Pregnancy (yes) & $1.71 \%$ & $2.44 \%$ & ns \\
\hline \multicolumn{4}{|l|}{ Internet use parameters } \\
\hline Internet connection frequency & & & $<.0001$ \\
\hline Less than one day/week & $33.75 \%$ & $20.23 \%$ & \\
\hline One day/week & $19.83 \%$ & $16.70 \%$ & \\
\hline More than one day/week but not daily & $35.02 \%$ & $37.17 \%$ & \\
\hline Daily & $11.40 \%$ & $25.90 \%$ & \\
\hline Seeking for sexual or medical advice on the Internet & $12.18 \%$ & $21.78 \%$ & $<.0001$ \\
\hline
\end{tabular}

Table 4 Binary regression characterizing females exposed to pornography $^{\mathrm{a}}$

\begin{tabular}{lll}
\hline Variable & $\begin{array}{l}\text { UE/WE Adjusted } \\
\text { odds ratio (95\% } \\
\text { confidence interval) }\end{array}$ & $p$ \\
\hline Sample characteristics & $.94(.87-1.02)$ & $\mathrm{ns}$ \\
Age & $.69(.51-.95)$ & $<.05$ \\
Father's education status (low) & $1.52(1.26-1.85)$ & $<.0001$ \\
Academic track (student) & $1.28(1.09-1.5)$ & $<.01$ \\
Sensation-seeking & $1.29(1.05-1.59)$ & $<.05$ \\
Perceived pubertal timing (early) & & \\
Internet use parameters & & $<.01$ \\
Internet connection frequency & $1.46(1.15-1.87)$ & $<.0001$ \\
$\quad \begin{array}{l}\text { More than one day/week } \\
\text { but not daily }\end{array}$ & $2.99(2.01-4.46)$ & $<.0001$ \\
$\begin{array}{l}\text { Daily } \\
\text { Seeking for sexual or medical } \\
\text { advice on the Internet }\end{array}$ & $1.8(1.35-2.41)$ & \\
\hline $\begin{array}{l}\text { The logistic regression uses explanatory factors selected from the } \\
\text { bootstrap procedure }\end{array}$ &
\end{tabular}

health/sexual-advice seekers on the Internet seem to be at higher risk for UE, seeking out health/sexual advice on the Internet should theoretically be associated to UE and not to WE. However, our results were consistent with this hypothesis for girls, but depicted exactly the opposite profile for males, with an association between health/sexual-advice seeking and WE but not UE. A possible explanation for this phenomenon could be that males who deliberately watch pornography are also more curious about sexual health issues in general. This hypothesis would imply that being better informed, online pornography seeking would not necessarily be associated with risky sexual behavior.

For that matter, our findings demonstrated that the majority of risky sexual behaviors, such as early sexual initiation, multiple sexual partners or a history of pregnancy were not associated with SEM exposure whether it was voluntary or not. These findings were in contradiction with some studies carried out in the U.S. on an association between multiple sexual partners and global (Wingood et al., 2001) or online (Braun-Courville \& Rojas, 2009) pornography exposure. These contradictory 
results could be due to the fact that in Switzerland there probably is a high level of sexual health literacy and adolescents might therefore be less influenced by sexual activities they might see on the Internet. Indeed, when comparing our data (not shown) and data from the Youth Risk Behavior Surveillance System in 2003 (in order to be comparable with our results), even though Swiss adolescents were more likely to have experienced lifetime SI or to have four or more sexual partners, they were less likely to start their sexual activity very early (before the age of 13) and to have not used a condom at last SI (National Center for Chronic Disease Prevention and Health Promotion, 2009).

Nevertheless, consistent with other research (Peter \& Valkenburg, 2006; Wingood et al., 2001), we found a statistically significant association between pornography exposure among males (whether it was deliberate or not) and non condom-use at last sexual intercourse. This issue raises some concern as the impact of this behavior on the transmission of infectious diseases has been largely demonstrated. The fact that WE and UE to online pornography was associated with non-condom use suggests that it is not the actual willingness of being exposed to pornography which can be considered as the trigger for risky sexual behaviors. Therefore, it could also be hypothesized that adolescents exposed to SEM could be in a stable relationship [with lower risk for sexually transmitted infections (STIs)] and using other forms of contraception. Although condom-use rates are higher in Switzerland than in the U.S. (National Center for Chronic Disease Prevention and Health Promotion, 2009), another explanation could be that the condom is still mainly seen as a means of birth control rather than a protection against STIs. The issues raised by this association should be further investigated in order to provide adequate prevention messages, without incorrectly impeaching SEM exposure as an inevitable trigger factor.

An interesting point to be mentioned is that, even if we did not find associations between SEM exposure and risky sexual behavior in our research, sensation-seeking remained associated with deliberate pornography exposure among boys and $\mathrm{WE} / \mathrm{UE}$ among girls. These results agree with the literature indicating a link between sensation-seeking attitudes and behaviors and pornography exposure (Brown \& L'Engle, 2009; Peter \& Valkenburg, 2006). However, as these studies did not analyze their samples by gender, we cannot precisely compare our results. Our explanatory hypothesis would be that being higher sensation-seekers, WE boys and UE/WE girls are involved in more exploratory behaviors, such as pornography-seeking or high-risk behaviors on the Internet.

Regarding sexual developmental aspects and consistent with other research indicating that early maturing girls had more sexual interest (Brown et al., 2005) and that early maturers were sexually more active (Michaud, Suris, \& Deppen, 2006), we found that early pubertal status was associated with online pornography exposure among females. That pubertal timing was not associated with SEM exposure among boys could be explained by the fact that pornography seeking is more rooted in societal norms for boys, whereas for girls, this behavior could be seen as more deviant and therefore also less practiced or at least less admitted by them.

The last point which emerged from our results was the strong association between online pornography exposure and bi-or homosexuality among male participants. Indeed, it has been suggested that the Internet is a good place for people from sexual minorities to exchange experiences without having to support the social stigmatization which often occurs in offline settings. Especially adolescents whose "coming out" has maybe not yet taken place and whose environment does not provide enough information about sexual orientation might perceive X-rated websites as a substantial source of sexual exploration, information or arousal (McFarlane et al., 2002). In that perspective, it seems important for health care practitioners, but also for parents and school-professionals dealing with adolescents, to keep in mind the importance of providing information about bi- and homosexuality, in order to open the door for possible questions from youth who are not yet sure of their sexual orientation.

The main strength of our study was that, to our knowledge, this was the first large study using a nationally representative sample to assess the correlates of risky sexual behavior and online pornography among adolescents, and whether their exposition was deliberate or not, comparing them to a nonexposed control group.

This study had several limitations. First, the cross-sectional design of the survey does not allow for any interpretation about causality. Second, as the data were self-reported and related to a very intimate topic, a response bias cannot be excluded. Moreover, as suggested by other (e.g., Wolak et al., 2007), participants might have characterized their pornography exposure as unwanted because they were embarrassed to admit they sought out such material. However, the literature indicates that selfadministered anonymous questionnaires encourages candid reporting, especially for sensitive topics (Brener, Billy, \& Grady, 2003; Kann, Brener, Warren, Collins, \& Giovino, 2002; Lothen-Kline, Howard, Hamburger, Worrell, \& Boekeloo, 2003). Third, as no clear definition of pornography was given in the questionnaire, participants could have understood this term in different ways. For instance, some adolescents could have included seeing once the picture of a naked person, whereas others would consider pornography only when they were actually viewing SI. Fourth, as our data were collected in 2002, Internet use parameters could have changed in terms of speed of connection and number and type of spams spread out, which could currently imply an increase in UE compared to 2002. However, as we considered only the Internet-using population, the characteristics of online pornography exposure have probably changed in a negligible way for the WE group. Finally, as it was a school-based survey, adolescents who do not follow 
mainstream schooling or youths who were absent from school the day of the survey, were not enrolled. Thus, as survey dropouts have previously been characterized as higher risk-taking adolescents (Michaud, Delbos-Piot, \& Narring, 1998) and may have more free time to spend on the Internet, online pornography exposure might be somewhat under-estimated in our research.

In conclusion, our findings indicate that, except for the neglected use of condoms among male participants, pornography exposure, whether it was deliberate or not, was not associated with risky sexual behavior among youths. With respect to involvement in risky sexual behavior, online pornography exposure seems to be a negligible risk factor. Health care practitioners should keep in mind the importance of providing sufficient information about all sexual orientations, and stress the importance of condom use, especially among young males who have been exposed to online pornography. More than looking at pornography exposure as a risk factor for risky sexual behavior, it could be used as a starter point for discussions about sexuality with adolescents.

Acknowledgments Study concept and design: Luder, Pittet, Surís, Akré, Berchtold, and Michaud. Acquisition of data: Michaud. Analysis and interpretation of data: Luder, Pittet, Berchtold, and Surís. Drafting of the article: Luder and Surís. Critical revision of the article: Pittet, Surís, Akré, Berchtold, and Michaud. Statistical analysis: Luder, Pittet, Berchtold, and Surís. Obtained funding: Michaud. The SMASH02 survey was carried out with the financial support of the Swiss Federal Office of Public Health (contract 00.001721/2.24.02.-81) and participating cantons. The funding bodies had no role in the design and conduct of the study; in the collection, analysis and interpretation of data; or in the preparation, review or approval of the manuscript. The survey was performed within a multicenter multidisciplinary group from the Institute of Social and Preventive Medicine, University of Lausanne [F. Narring, MD, MSc (Principal investigator); V. Addor, RN, MPH; C. Diserens, MA; A. Jeannin, MA; G. van Melle, PhD; and P.-A. Michaud]; the Institute for Psychology, University of Bern (F. Alsaker, PhD; A. Bütikofer, MA; and A. Tschumper); and the Sezione Sanitaria, Dipartimento della sanità e della socialità, Canton Ticino (L. Inderwildi Bonivento, MA).

\section{References}

Alsaker, F. D. (1992). Pubertal timing, overweight, and psychological adjustment. Journal of Early Adolescence, 12, 396-419.

Austin, P. C., \& Tu, J. V. (2004a). Bootstrap methods for developing predictive models. American Statistician, 58, 131-137.

Austin, P. C., \& Tu, J. V. (2004b). Automated variable selection methods for logistic regression produced unstable models for predicting acute myocardial infarction mortality. Journal of Clinical Epidemiology, $57,1138-1146$.

Berg-Kelly, K., \& Erdes, L. (1997). Self-assessment of sexual maturity by mid-adolescents based on a global question. Acta Paediatrica, $86,10-17$.

Braun-Courville, D. K., \& Rojas, M. (2009). Exposure to sexually explicit web sites and adolescent sexual attitudes and behaviors. Journal of Adolescent Health, 45, 156-162.

Brener, N. D., Billy, J. O., \& Grady, W. R. (2003). Assessment of factors affecting the validity of self-reported health-risk behavior among adolescents: Evidence from the scientific literature. Journal of Adolescent Health, 33, 436-457.

Brown, J. D., Halpern, C. T., \& L'Engle, K. L. (2005). Mass media as a sexual super peer for early maturing girls. Journal of Adolescent Health, 36, 420-427.

Brown, J. D., \& L'Engle, K. L. (2009). X-rated sexual attitudes and behaviors associated with US early adolescents' exposure to sexually explicit media. Communication Research, 36, 129-151.

Duimel, M., \& DeHaan, J. (2007). New links in the family: The digital world of teenagers and the role of their parents. Retrieved July 1 , 2009 from http://english.scp.nl/english/publications/summaries/ 9789037702873.html.

Gniech, G., Oettling, T., \& Brohl, M. (1993). Untersuchungen zur Messung von "Sensation Seeking”. Bremer Beiträge zur Psychologie, Nr.110. Germany: Universität Bremen.

Goodson, P., McCormick, D., \& Evans, A. (2001). Searching for sexually explicit materials on the Internet: An exploratory study of college students' behavior and attitudes. Archives of Sexual Behavior, $30,101-118$.

Haggstrom-Nordin, E., Hanson, U., \& Tyden, T. (2005). Associations between pornography consumption and sexual practices among adolescents in Sweden. International Journal of STD and AIDS, $16,102-107$.

Hald, G. M., \& Malamuth, N. M. (2008). Self-perceived effects of pornography consumption. Archives of Sexual Behavior, 37, 614625.

Holsen, I., Kraft, P., \& Vitterso, J. (2000). Stability in depressed mood in adolescence: Results from a 6-year longitudinal panel study. Journal of Youth and Adolescence, 29, 61-78.

Jeannin, A., Narring, F., Tschumper, A., Bonivento, L. I., Addor, V., Butikofer, A., et al. (2005). Self-reported health needs and use of primary health care services by adolescents enrolled in postmandatory schools or vocational training programmes in Switzerland. Swiss Medical Weekly, 135, 11-18.

Kann, L., Brener, N. D., Warren, C. W., Collins, J. L., \& Giovino, G. A. (2002). An assessment of the effect of data collection setting on the prevalence of health risk behaviors among adolescents. Journal of Adolescent Health, 31, 327-335.

Kanuga, M., \& Rosenfeld, W. D. (2004). Adolescent sexuality and the internet: The good, the bad, and the URL. Journal of Pediatric and Adolescent Gynecology, 17, 117-124.

Lo, V., \& Wei, R. (2005). Exposure to internet pornography and Taiwanese adolescent's sexual attitudes and behaviors. Journal of Broadcasting \& Electronic Media, 49, 221-237.

Lothen-Kline, C., Howard, D. E., Hamburger, E. K., Worrell, K. D., \& Boekeloo, B. O. (2003). Truth and consequences: Ethics, confidentiality, and disclosure in adolescent longitudinal prevention research. Journal of Adolescent Health, 33, 385-394.

McFarlane, M., Bull, S. S., \& Rietmeijer, C. A. (2002). Young adults on the Internet: Risk behaviors for sexually transmitted diseases and HIV. Journal of Adolescent Health, 31, 11-16.

Michaud, P. A., Delbos-Piot, I., \& Narring, F. (1998). Silent dropouts in health surveys: Are nonrespondent absent teenagers different from those who participate in school-based health surveys? Journal of Adolescent Health, 22, 326-333.

Michaud, P. A., Suris, J. C., \& Deppen, A. (2006). Gender-related psychological and behavioural correlates of pubertal timing in a national sample of Swiss adolescents. Molecular and Cellular Endocrinology, 254-255, 172-178.

National Center for Chronic Disease Prevention and Health Promotion. (2009). Healthy youth! YRBSS. Youth online: Comprehensive results. Retrieved from http://apps.nccd.cdc.gov/yrbss/CategoryQuestions. asp?Cat $=4 \&$ desc $=$ Sexual $\% 20$ Behaviors.

Peter, J., \& Valkenburg, P. M. (2006). Adolescents' exposure to sexually explicit material on the Internet. Communication Research, 33, 178-204. 
Rideout, V. (2009). Generation Rx.com. How young people use the internet for health information. Retrieved June 17, 2009 from http://www.kff.org/entmedia/2011211a-index.cfm.

Sabina, C., Wolak, J., \& Finkelhor, D. (2008). The nature and dynamics of internet pornography exposure for youth. Cyberpsychology \& Behavior, 11, 691-693.

Stulhofer, A., Busko, V., \& Landripet, I. (2010). Pornography, sexual socialization, and satisfaction among young men. Archives of Sexual Behavior, 39, 168-178.

Wingood, G. M., DiClemente, R. J., Harrington, K., Davies, S., Hook, E. W., \& Oh, M. K. (2001). Exposure to X-rated movies and adolescents' sexual and contraceptive-related attitudes and behaviors. Pediatrics, 107, 1116-1119.

Wolak, J., Mitchell, K., \& Finkelhor, D. (2007). Unwanted and wanted exposure to online pornography in a national sample of youth Internet users. Pediatrics, 119, 247-257.

Ybarra, M. L., \& Mitchell, K. J. (2005). Exposure to internet pornography among children and adolescents: A national survey. Cyberpsychology \& Behavior, 8, 473-486.

Zillmann, D. (2000). Influence of unrestrained access to erotica on adolescents' and young adults' dispositions toward sexuality. Journal of Adolescent Health, 27, 41-44. 